\title{
Maloclusiones en dentición mixta en un grupo de niños Venezolanos VIH/SIDA
}

\section{Resumen}

En niños VIH/SIDA son múltiples las patologías bucales siendo las maloclusiones en dentición mixta las menos estudiadas. Objetivo: Determinar las maloclusiones dentales presentes en niños VIH/SIDA que acudieron al CAPEI/UCV. Materiales y métodos: Estudio descriptivo transversal y prospectivo en una muestra de 53 niños VIH/ SIDA que acudieron al CAPEI/UCV durante el año 2011, se analizaron los tipos de maloclusión dental y la prevalencia de maloclusiones. Resultados: La edad media fue 8,5 años, la prevalencia
María Elena Guerra ${ }^{1}$ Aida C Medina ${ }^{2}$

William Carrasco ${ }^{2}$

Elizabeth Albornoz ${ }^{3}$

Artigo Original

\section{Más oclusões na dentição mista em um grupo de crianças venezuelanas portadoras de HIV/AIDS}

\section{Resumo}

Em crianças portadoras de HIV/AIDS são múltiplas as patologias bucais sendo as más oclusões na dentição mista as menos estudadas. Objetivo: Determinar as más oclusões dentárias presentes em crianças portadores de HIV / AIDS frequentadoras do CAPEI/UCV. Mate- de maloclusiones fue de un $100 \%$, el $100 \%$ presentó perdida prematura de algún diente primario, La maloclusión más frecuente fue la Clase II, observandose en 29 pacientes $(54,7 \%)$ seguida de clase I en 21 pacientes ( $40 \%$ ) que corresponden en su totalidad a Clase I tipo 5 causada por perdida prematura del molares primarios y Clase III en 3 pacientes (5\%). Conclusión: Resaltamos que perdida prematura de dientes primarios la etiología más frecuente de las maloclusiones.

Palabras clave: Niños VIH/SIDA; maloclusiones, pérdida prematura de dientes primarios.

\footnotetext{
${ }^{1}$ Profesora Titular. Coordinadora del Programa “El Binomio Madre e Hijo VIH/SIDA CAPEI/UCV“marielena05@gmail.com 58(212)6053800.

2 Profesores Asociados. Cátedra de Odontología Infantil 58(212)6053803.

${ }^{3}$ Profesora Agregada. Coordinadora del CAPEI/UCV 58(212)6053800.
}

riais e métodos: Estudo descritivo transversal e prospectivo em uma mostra de 53 crianças portadoras de HIV/AIDS que compareceram ao CAPEI/UCV durante o ano 2011. Foram analisados os tipos e a prevalência das más oclusões dentárias. Resultados: A idade média foi de 8,5 anos, a prevalência de má oclusão foi de $100 \%$, e $100 \%$ apresentou perda precoce de algum den- 
te decíduo. A má oclusão mais frequente foi a Classe II, observada em 29 pacientes $(54,7 \%)$ seguida de classe I em 21 pacientes ( $40 \%$ ) que correspondeu em sua totalidade a Classe I tipo 5 causada por perda precoce de molares decíduos e Classe III em 3 pacientes (5\%). Conclusão: sa- lientamos que a perda precoce de dentes decíduos é a etiologia mais frequente das más oclusões.

Palavras chave: Criança, Infecções por HIV, Má Oclusão, Dente Decíduo, Perda de Dente.

Original article

\section{Malocclusions in mixed dentition in a group of Venezuelan children HIV/AIDS}

\begin{abstract}
In HIV / AIDS children are multiple oral patlogies being malocclusions in mixed dentition the least studied. Objetive: To determine dental malocclusions in children HIV/AIDS attended in CAPEI/UCV. Materials and methods: Cross-sectional and prospective descriptive study on a sample of 53 HIV / AIDS children that attended CAPEI/UCV during 2011. Results: Analysed dental malocclusion types and prevalence of malocclusions the mean age was 8.5 years, the prevalence of malocclusions was $100 \%$, males were the most affected $30(56.6 \%)$, $100 \%$ had premature loss of a primary toothThe most common malocclusion was class II, noting on 29 patients (54.7\%) followed by class I in 21 patients (40\%) that correspond in full in 3 patients $(5 \%)$ and class I type 5 caused by lost premature primary molarclass III. Conclusion: We underline that lost the most frequent of malocclusions etiology premature of primary teeth.
\end{abstract}

Key words: HIV / AIDS children; malocclusions; premature lost of primary teeth.

\section{Introducción}

El Virus de la Inmunodeficiencia Humana, (VIH), es un lentivirus, subfamilia de los Retrovirus. Se trata de un ARN de cadena única, caracterizándose fundamentalmente por tener un tropismo especial por células con receptor de superficie CD-4; aunque también invade otras sin dicha molécula, por su variabilidad genética, lo que puede condicionar distintas cepas en un mismo individuo afectado. El primer contacto conocido ocurrió en el año de 1931 en África. La primera muestra de sangre infectada por el virus está guardada desde 1950, pero la primera manifestación de la enfermedad ocurrió en la ciudad de San Francisco, Estados Unidos, a principios de la década de 1980. La calidad de vida de las personas infectadas con el VIH cambió. Hoy, después de este avance de la ciencia, la lucha para controlar y erradicar la enfermedad no se detiene. Mientras tanto continúan las esperanzas para encontrar una vacuna y concientizar a las personas de que el sida es un asunto de todos ${ }^{1}$.

Los niño/as y los jóvenes afectados por el VIH son la "cara oculta" del SIDA, y no sólo porque 
están ausentes de las discusiones de política global y nacional sobre VIH/SIDA. Más grave aún: carecen de acceso a los servicios de atención y de prevención más básicos². Estos servicios de atención incluyen los tratamientos odontológicos3. Desde 1998 se han atendido pacientes pediátricos VIH/SIDA en la Facultad de Odontología de la Universidad Central de Venezuela consientes de esa situación se creó en Centro de Atención a Pacientes con Enfermedades Infectocontagiosas (CAPEI/UCV). El cual ofrece tratamiento sin ningún tipo de discriminación a pacientes VIH/SIDA ${ }^{3}$.

En la literatura se encuentran numerosos trabajos en los cuales se estudia la relación de la maloclusiones dentales en niño/ as ${ }^{4,5,6,7,8,9,10}$, pero no encontró ningún trabajo en cual analizaran, evaluaran o determinara las maloclusiones dentales en niños/as VIH/SIDA.

La oclusión normal es la relación interdental superior e inferior más equilibrada para cumplir con la función masticatoria y preservar la integridad de la dentición a lo largo de la vida en armonía con el conjunto estructural al que denominamos aparato bucal. En Odontología, observamos con frecuencia maloclusiones dentales, las cuales se han definido como cualquier desviación de la oclusión ideal (amplia gama de posibilidades que entra dentro de lo normal) ${ }^{5}$. La Odontopediatría y Ortodoncia preventiva, estudian el análisis del desarrollo y evolución de las maloclusiones, lo que resulta fundamental en la elección de los procedimientos empleados para evitarlas o detenerlas interfiriendo en su evolución ${ }^{4}$.

La prevalencia de maloclusiones indica que aproximadamente un tercio de la población tiene una oclusión que puede considerarse como "normal" o casi, mientras que unos dos tercios tienen algún grado de maloclusión. De estos últimos, solo un pequeño grupo (un $5 \%$ según Proffit $)^{5}$ tiene una maloclusión atribuible a una causa específica, conocida, como por ejemplo un déficit mandibular por una fractura del cóndilo mandibular, una maloclusión característica que acompaña a un síndrome genético u otras causas conocidas. Se observa que, la mayoría de individuos con maloclusiones son el resultado de una combinación compleja y todavía mal comprendida de influencias genéticas y ambientales y no están causadas por un proceso patológico sino por variaciones más o menos moderadas del desarrollo normal.

Las maloclusiones dentales están estrechamente relacionadas a la salud dental en dentición primaria, la caries y la posición de los dientes primarios pueden ser determinantes de la presencia de maloclusiones en etapas posteriores ${ }^{4,5,6,7,8}$.

El estudio sobre la política de salud bucal para la prevención y atención oportuna del preescolar y el estudio sobre las maloclusiones, las necesidades odontológicas nacionales y las políticas sanitarias, realizados por FUNDACREDESA (Fundación centro de estudios sobre crecimiento y desarrollo de la población venezolana), en los años 1983 y 1987, respectivamente; establecen que el estudio sobre la oclusión dental es una investigación que se encuentra relacionada con patrones nutricionales, influencia de estados psicológicos de stress emocional y hábitos bucales (principalmente succión del pulgar, succión del labio y deglución atípica, entre otros ${ }^{9}$.

El odontopediatra debería ser el primero en prevenir y realizar un diagnóstico de maloclusiones dentales, indicando las necesidades de tratamiento de acuerdo al tipo de oclusión, en el periodo de erupción se encuentra tomando en cuenta sus características individuales, en el 
Servicio de Ortodoncia Interceptiva del postgrado de Odontología Infantil de la Universidad Central de Venezuela, los estudiantes brindan atención de ortodoncia a pacientes pediátricos y proyectan ese conocimiento a la comunidad.

Lo anteriormente expuesto nos motivó a mostrar a la comunidad las maloclusiones dentarias presentes en niño/as VIH/SIDA para llegar a establecer el tratamiento ortodóncico que necesitan los pacientes pediátrico que acuden al CA$\mathrm{PEI} / \mathrm{UCV}$.

\section{Antecedentes}

En el año 1998 se atendió el primer niño VIH/ SIDA en la Facultad de Odontología de la Universidad Central de Venezuela y aparece la necesidad en nuestra Facultad de atención odontológica para niños menores de 4 años portadores del Virus de Inmunodeficiencia Humana. Para el año 2000 había 15 pacientes pediátricos VIH/ SIDA, todos con necesidades de tratamiento odontológico muy complejo. Por su reducida edad, y presentar caries rampante, razones por las cuales fueron tratados bajo anestesia gene$\mathrm{ral}^{3}$.

Es bien conocido que los niños VIH/SIDA presentan una problemática mayor que los adultos, entre estos se mencionan: alteraciones de crecimiento y desarrollo corporal ${ }^{3}$. El inadecuado comportamiento psicosocial y en lo que se refiere a interés odontológico, están descritas manifestaciones bucales tanto en tejidos blandos y duros, ocupando un especial interés la caries dental ${ }^{10}$.

La caries dental y el VIH son dos enfermedades de origen microbiológico ${ }^{11 ; 12}$. En principio no son subsidiarias una de la otra, pero se ha observado un aumento considerado y un com- portamiento más agresivo en la caries dental de los niños VIH/SIDA cuando lo comparamos con los niños no infectados. El nivel de caries en la dentición primaria de niños VIH/SIDA es considerablemente mayor que el de la población pediátrica no infectada ${ }^{12}$, considerándose menos frecuentes los casos de estos niños libres de caries, esto ha sido motivo de estudio y se ha relacionado con la edad y estado de inmunosupresión Pareciera que los altos índices de caries en niños VIH/SIDA se deben a múltiples factores al igual que los niños no infectados, destacándose entre ellos factores locales y a defectos en la formación del diente. Se considera que los cambios en el flujo salival tienen relación con la caries de estos niños, pero no hay estudios clínicos suficientes que demuestren que esto es cierto, tal como lo afirman Howel \& col así como también Hicks \& $\operatorname{col}^{13 ; 14}$.

Los Primeros Molares Permanentes, son generalmente los primeros dientes permanentes que acompañan a la dentición primaria en la boca de un niño, transformando con su presencia la oclusión primaria, en mixta ${ }^{15}$. En un estudio realizado en Venezuela sobre la prevalencia de caries en el primer molar permanente $\mathrm{n}$ niños $\mathrm{VIH}(+) \mathrm{y}$ sus hermanos VIH (-). Se encontró que los niños $\mathrm{VIH}(+)$ presentaron caries en el primer molar permanente con un 57,6\% mientras que solo el 11,5\% se observó en los hermanos VIH (-) ${ }^{16}$.

La caries dental y la pérdida prematura de piezas dentales es una de las etiologías de la presencia de maloclusiones en la población general $^{17}$. Esto nos llevó a la necesidad de evaluar a estos niño/ as VIH/SIDA en este aspecto.

\section{Objetivo}

Determinar las maloclusiones dentales presentes en un grupo de niños venezolanos VIH/ 
SIDA que acudieron al CAPEI/UCV durante el año 2011.

\section{Material y métodos}

Tipo de estudio: Estudio descriptivo, transversal y prospectivo de los niños y niñas VIH/ SIDA que acudieron al CAPEI/UCV durante el año 2010.

Población: La muestra estuvo constituida por 53 pacientes en periodo de dentición mixta cuyos representantes bajo consentimiento informado aceptaron participar en este estudio.

Criterio de Inclusión: Todos los pacientes pediátricos VIH/SIDA que han estado sometidos a tratamientos odontológicos en el CAPEI/UCV previamente, tenían historia clínica y están bajo terapia antirretroviral y asistieron a consulta durante el año 2011 se les invitó a realizarse un examen bucal para estudiar maloclusiones.

Como criterio de Exclusión: no participaron en el estudio, aquellos niño/as que presentaban alteraciones endocrinas, ni estaban dentro de síndromes genético que cursaban con maloclusiones dentales.

Procedimiento: El examen clínico se realizó por medio de la observación directa en las instalaciones del CAPEI/UCV. Inspección de la cavidad bucal. El examen clínico al paciente se realizó con el niño/a sentado/a en el sillón dental con luz artificial proveniente del equipo dental, complementados con instrumental básico, con el espejo bucal se separaron los labios para observar la relación molar, y realizar el diagnóstico de la maloclusión dental, para el cual se tomó la Clasificación de Angle y modificación de Dewey-Anderson, que describimos a continuación. ${ }^{18,19,20,21,22,23}$
Clasificación de Angle con Modificación de Anderson. Fue a principios del siglo XX, cuando Edward Angle estableció una clasificación basada en la relación de cúspides entre los primeros molares superiores e inferiores, la cual ha sido tomada como patrón de referencia para las maloclusiones de origen dentario, así tenemos:

- Clase I: Cuando la cúspide mesiovestibular del primer molar superior ocluye en el surco vestibular del primer molar inferior.

- Clase II: Cuando la cúspide mesiovestibular del primer molar superior ocluye por delante de la cúspide mesiovestibular del primer molar inferior (división 1 y 2)

- Clase III: Cuando la cúspide mesiovestibular del primer molar superior ocluye por detrás de la cúspide distovestibular del primer molar inferior.

La clasificación de Angle fue ampliada por Anderson, y es la más utilizada hoy en día.

- Clase I: Normoclusión.

Tipo 1. Dientes superiores e inferiores apiñados, o caninos en labioversion, infralabioversion o linguoversion.

Tipo 2. Incisivos superiores protuidos o espaciados.

Tipo 3. Si uno o más incisivos están cruzados en relación con los inferiores.

Tipo 4. Mordida cruzada posterior (temporal o permanente), pero anteriores

Tipo 5. Si hay pérdida de espacio posterior por migración mesial del 6, mayor de $3 \mathrm{~mm}$. Protrusión bimaxilar. Posición de avance de ambas arcadas. Puede o 
no haber malposiciones individuales de los dientes y correcta forma de los arcos, pero la estética es afectada.

- Clase II. Distoclusión. Maxilar en posición mesial en relación al arco mandibular, y cuerpo de la mandíbula en relación distal con el arco maxilar.

Clase II división 1. Si los incisivos superiores se encuentran en labioversion.

Clase II división 2 .Si los incisivos centrales superiores se encuentran en posición casi normal o ligera linguoversion y los laterales se encuentran labial y mesialmente.

Clase II Subdivisión: Es cuando de un lado es Clase II y del otro es Clase I, estos pacientes presentan generalmente con un buen perfil, con un patrón estético adecuado, una altura vertical promedio o disminuido.

- Clase III. Mesioclusión. Mandíbula con relación mesial al maxilar

Tipo 1. Si observamos los arcos por separado, estos se ven de manera correcta pero la oclusión es a tope.

Tipo 2. Si los dientes superiores están bien alineados, los incisivos inferiores apiñados y posición lingual con respecto a los superiores.

Tipo 3. Si se presenta un arco mandibular muy desarrollado, y un arco maxilar poco desarrollado, los dientes superiores, a veces apiñados y en posición lingual con respecto a los inferiores, deformidad facial acentuada.
Subdivisión: Cuando de un lado sea Clase III y del otro Clase 1. Este grado de severidad puede variar desde una simple cúspide, hasta problemas ó

Se utilizó la Historia Clínica de infantil del CA$\mathrm{PEI} / \mathrm{UCV}$ que incluía variables sociodemográficas, un odontodiagrama para registrar caries, lesiones pulpares, patologías, dientes presentes $\mathrm{y}$ ausentes y un esquema para describir las maloclusiones presentes.

Dentro de las etiologías que originan maloclusiones dentales más relevantes para niños VIH/ SIDA tomamos:

Las enfermedades, generales y locales. Dentro de la cuales estas el VIH/SIDA, por presentar los niño/as que la padecen, alto porcentaje de caries, problemas nutricionales y de crecimiento y desarrollo ${ }^{3}$.

Las características sociodemográficas. Bajo ingreso familiar, Higiene bucal inadecuada. No asistencia regular a la consulta dental, Alimentación desbalanceada. Estas características intervienen indudablemente en la alteración del desarrollo de la oclusión dentaria. Sin embargo, la educación sobre la importancia de la higiene bucal, el cuidado de la dentición primaria y otras, la atención odontológica continua (visitas cada 3 meses), que se les remienda a los niño/ as VIH/SIDA desde edades muy tempranas, contribuyen al desarrollo y buen funcionamiento de la oclusión dentaria en el adulto Además la calidad y consistencia de la dieta influye en el correcto desarrollo de los maxilares tal como lo refieren en un estudio epidemiológico de la oclusión dental en escolares de Envigado, realizado en Colombia ${ }^{24}$.

Pérdida prematura de molares primarios. Una parte importante de la prevención de la malo- 
clusión es el manejo adecuado de los espacios creados por la pérdida de los dientes primaros, fundamentalmente molares, la pérdida prematura estos dientes es otra causa local de alteraciones de la oclusión. Los dientes primaros desempeñan un papel muy importante en el mantenimiento de la longitud del arco, la pérdida precoz provoca una disminución del espacio reservado para el sucesor permanente, debido a la migración de los dientes adyacentes y el consiguiente acortamiento de la longitud de la arcada. Los efectos perjudiciales a largo tiempo varían y dependen de una serie de circunstancias, como el grado de desarrollo del sucesor permanente, el tipo de diente temporal que se pierde, las características previas existentes en la arcada y el momento en el cual el paciente acude al odontólogo 25 .

Caries proximales profundas. La caries dental, sobre todo las interproximales profundas en molares temporales, ocasionan acortamientos de la longitud de la arcada dentaria por migraciones de los dientes vecinos. Todas las lesiones cariosas deben ser restauradas de una manera adecuada, no sólo para evitar la infección y la pérdida de dientes, sino para conservar la integridad de las arcadas dentarias ${ }^{26}$.

Análisis de los datos: La transcripción de datos y procesamiento de los mismos se realizó usan-

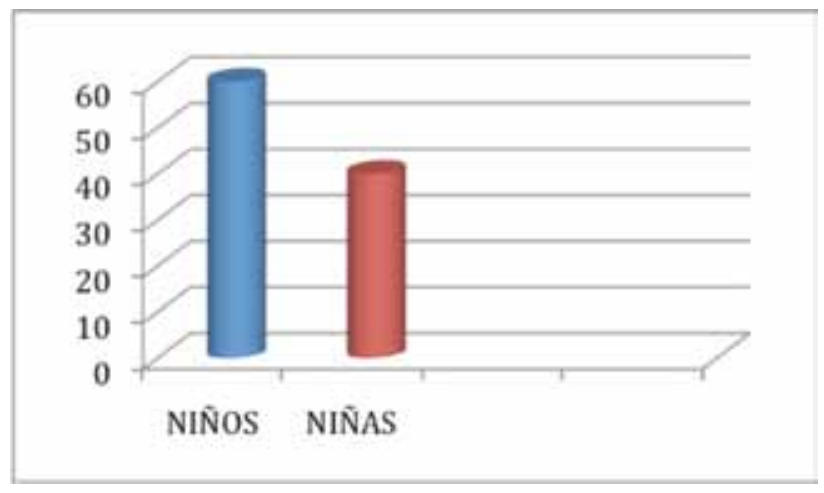

Gráfico 1. Distribución de acuerdo a la presencia de maloclusiones de acuerdo al género.

Fuente: CAPEI/UCV 2011.

do el software estadístico SPSS así como el empleo del análisis de los datos.

\section{Resultados}

El 100\% de los niños presentó algún tipo de maloclusión dental.

Según el género se observó un mayor porcentaje del masculino 30 pacientes $(56,6 \%)$, que en el femenino $23(43,3 \%)$ (Gráfico 1).

En relación al tipo de maloclusión dental más frecuente fue la clase II, observandose en 29 pacientes $(54,7 \%)$ seguida de clase I en 21 pacientes (40\%) que corresponden en su totalidad a Clase I tipo 5 causada por perdida prematura del mo-

Tabla 1. Distribución de acuerdo a la presencia de maloclusiones dentales observadas en los niños según clasificación de Angle y modificación de Dewey-Anderson.

\begin{tabular}{|c|c|c|}
\hline Maloclusión & Pacientes & Porcentaje \\
\hline Clase I tipo 5 & 21 & 40,6 \\
\hline Clase II & 29 & 54,7 \\
\hline Clase III & 3 & 5,6 \\
\hline Total & 53 & 100 \\
\hline
\end{tabular}

Fuente CAPEI/UCV 2011. 
lares primarios y en 3 pacientes (5\%) Clase III (Tabla 1).

A pesar de no estar dentro de la Clasificación de Angle y modificación de Dewey-Anderson. Nos llamó la atención que observamos mordida abierta anterior se observó en 27 niños (51\%), por ser más de la mitad de los niños nos pareció relevante señalarlo en el trabajo.

Según el nivel socioeconómicos, el 54,7\% nivel bajo y el 30,5\% (24) de nivel marginal. Según la ocupación de la madre el 80\% (38) eran ama de casa y el 20\% (15) restantes eran huérfanos, todos referían ir a la escuela.

\section{Discusión}

En nuestro estudio se observó la mordida abierta anterior en un $51 \%$ superior a lo reportado en estudios realizados en Dar es Salaam (Tanzania) en 698 niños y adolescentes entre los 6 y los 18 años de edad, en el cual se encontró que la alteración más frecuente fue la mordida abierta anterior, entre el 9 y el 13\% para todos los gru$\operatorname{pos}^{26,27}$.

Al igual que otros estudios en el presente trabajo el diagnóstico de la maloclusión se basa en la relación del primer molar permanente, en la relación canina primaria y relación incisiva. El diagnostico se realizó de manera dinámica tomando en consideración aquellos factores correspondientes a la edad, estado de desarrollo de la dentición en cada paciente y empleamos como clasificación la Angle ya que esta ha sido empleada como parámetro en multiples estudios epidemiológicos en nuestro país y en el mundo entero ${ }^{11 ; 12 ; 21 ; 27,28,29,30,31}$.

El género más afectado en nuestro estudio fue el masculino con un $56 \%$ a diferencia de otro estu- dio realizado también en grupo de niños venezolanos que fue el femenino con un $53 \%{ }^{32}$.

En nuestro grupo de estudio la perdida prematura fue la etiología más frecuente de maloclusión, la literatura reporta que la perdida de espacio derivada por perdidas prematuras constituye un problema oclusal severo ya que en muchos casos el espacio perdido no puede ser reganado, lo que produce un discrepancia negativa que puede llevar a la necesidad de la exodoncia de dientes permanentes por que se produce un colapso vertical, alteraciones oclusales en todos los planos y desviación del sucesor. Sin embargo esta situación es desapercibida no solo por representantes sino también por algunos odontólogos ${ }^{33,34,35,36}$.

Según la Organización Mundial de la Salud (OMS) citado por Ortiz ${ }^{35}$, las maloclusiones ocupan el tercer lugar de prevalencia dentro de las patologías en Salud bucodental, luego de la caries dental y de la enfermedad periodontal. En Latinoamérica según datos de la Organización Panamericana de la Salud OPS, existen altos niveles de incidencia y prevalencia de maloclusiones que superan el $85 \%$ de la población ${ }^{35}$ al igual que en nuestro trabajo realizado en niño/ as VIH/SIDA Venezolanos.

En cuanto al nivel socioeconómico en nuestro estudio se encontró que los pacientes pertenecían a los niveles más bajos, así como sus madres son amas de casa, tal y como hemos ido describiendo en estudios anteriores en el CAPEI/ $\mathrm{UCV}^{3 ; 12}$.

\section{Conclusiones}

Los factores de riesgos en los niño/ as VIH/SIDA son múltiples y aparecen desde la dentición primaria. Se destacan las perdidas prematuras de dientes como la etiología de maloclusiones más frecuente observada en este grupo. 


\section{Referencias}

1. Universidad Nacional de Colombia. Sida ahora una enfermedad controlable http:/ / historico.unperiodico.unal.edu. co (Consultada12/10/2012)

2. UNICEF Los niños VIH son la cara oculta del SIDA www.unicef.es (Consultada10/10/2012)

3. Guerra ME; Casanova ME; Suarez JA; Salazar A. Tratamiento odontopediatrico de un paciente VIH (+) bajo anestesia general; primer caso en el postgrado de Odontología infantil en la Facultad de Odontología Universidad Central de Venezuela. Acta odontol. venez, Caracas, v. 41, n. 1, enero 2003

4. Sarabia J. Ortodoncia preventiva: mito o realidad? . Resumen de Conferencia dictada 4ta reunión anual AMOM.Colombia ,1999 www.amom.com.mx (Consultada 8/10/2012)

5. Proffit W R. The etiology of the orthodontic problems. In: Proffit W R, Fields H W (Eds). Contemporary Orthodontics 2nd Edition. St. Louis: Mosby, 1993: 105-136.

6. Giaquinta MA El Valor de la Salud 2009 disponible en http:/ / www.forumglobal.org (Consultada 12/10/2012)

7. Quirós O. Ortodoncia Nueva generación Caracas AMULCA; 2003. www.odontocat.com (Consultada12/10/2012)

8. Proffit WR, Fields HW. Ortodoncia Conteporánea teoria y práctica. 3 Ed. Madrid: Harcourt;2001

9. Mijares A. Estudio sobre la política de salud bucal para la prevención y atención oportuna del pre-escolar. Fundacredesa. Caracas, 1983

10. Velasco E. Odontoestomatología y SIDA. Un enfoque multidisciplinario. SecciónIII ESPAXS Publicaciones Médicas Barcelona (2002):185-194.

11. Acevedo, AM. Indicadores epidemiológicos de caries dental en una población de bajos recursos en el Municipio Sucre, Edo. Miranda, Venezuela. Revista Venezolana de Investigación Odontológica.(1999): 1:55-58

12. Guerra ME; Tovar V. Atención Odontológica a niños VIH (+). Archivos Venezolanos de Puericultura y Pediatría. (2001) Dici: 64 (4)

13. Howel RB; Houp M. More than one factor can influence caries development in HIV positive children. Pediatric - Dent (1991) Jul-Aug; 13 (4): 247

14. HICKS, John y cols. Dental caries in HIV-infected children: a longitudinal study. Pediatric Dentistry. (2000):22(5); 359-363

15. Escareño, C: Manual de Actividades Clínicas de Odontopediatría. Capítulo I y XIII. Universidad Autónoma Metropolitana. Primera edición (1990). Editorial trillas. México.

16. Guerra María E; Rodríguez Carla; Carrasco William; Tovar Vilma; López Lydia. Prevalencia de caries en el primer molar permanente niños VIH (+) vs. VIH (-) Acta Odontológica Venezolana Vol 48;No 1; 2013

17. Segura Martinez N. Perdida prematura de dientes temporales y maloclusión en escolares. Policlinica "Pedro Díaz Coello"(tesis). Holguin Facultad de Ciencias Médicas;2003

18. Medina C. Prevalencia de Maloclusiones Dentales en un grupo de pacientes pediátricos Acta Odontológica Venezolana Vol 48;No 1; 2010

19. Angle EH. Classification of Malocclusion. Dental Cosmos 1899:41:248-64

20. Angle EH. Malocclusion of the teeth. 7 ma ED, SS White Dental Mig CD Philadelphia 1907

21. Dewey M. Practical Orthodontia. 4ta ED. CV Mosby,St Louis Mi USA,1919,pp 45-69

22. Anderson G. Practical Orthodontics. 9na Ed. The Mosby Co St Louis Mi USA, 1960

23. Saturno, L. Características de la oclusión de 3630 escolares del área metropolitana. Acta Odontológica Venezolana 1980;2:237-263

24. Paola A. Urrego-Burbano, Lina P. Jiménez-Arroyave, Miguel A. Londoño-Bolívar, Mario Zapata-Tamayo; Paola Botero-Mariaca. Perfil epidemiológico de la oclusión dental en escolares de Envigado, Colombia Revistade Salud Publica Vol.13,No6;2011 
25. Aristizábal Restrepo Carolina; Chemás Oviedo, Lina María; Arango Larrarte, Alberto. Frecuencia de perdida de espacio por exodoncia de dientes temporales en la unidad Materno-Infantil de la Policlinica Nacional Univit Odontol $200323(51) ; 13-17$

26. Duque de Estrada Riverón J. Factores de Riesgo asociado con las caries dental en niños. Rev Cubana Estomatol.2003;40(1): 13-5

27. Oka AE, N'Cho KJ, Kattie AL, Koffi NA, Bakayoko LR. Influence of food quality and quantity on children's teeth. OdontostomatolTrop. 2003;26(102):5-12

28. Mugonzinhwa EA. Variations in occlusal and space characteritic in a series of 6-18 years old in Itala District. Tanzania. Afr Dent, J 1992; (16):17-22

29. Keski-Nisula K, Lehto R, Lusa V, Keski-Nisula L, Varrela J. Ocurennce of malocclusion and need of orthodontic tratment in early mixed dentition. Am J Orthod Dentofacial Orthop 2003; 124:631-8

30. Schwertner A, Nouer Para, Garbui Ju, Kuramae M. Prevalencia de maloclusao em criancans entre 7 e 11 anos em Foz do Iguazu PR.RGO Porto Alegre 2007;55;155-61

31. Mitchell L. The aetiology and classication of malocclusio. En An Introducction to Orthodontics. Oxford University Press , Oxford, 1999

32. Medrano JE, Cedillo LS, Murrieta IF. Prevalencia de factores de riesgo para el desarrollo de la oclusión. Revista ADM 2002;59 (4):128:133

33. Rojas, Ginette; Brito Hairo;Díaz José; Soto, Sonia; Alcedo Carolina; Quirós Oscar, D.Jurisc Aura; Fuen mayor, Dorathis; Maza Patricia;Ortiz, Monica. Tipo de Maloclusiones dentales más fecuentes en los pacientes de Diplomado de Ortodoncia Interceptiva de la Universidad Gran Mariscal de Ayacucho. www.ortodoncia.ws (consultada 10/2/2012)

34. Barrachina Mataix C. Etiopatogenia: factores locales. En: Canut Bruzola JA. Ortodoncia clínica y terapéutica. España:Masson, 2000: 221-42.Smith Corgel E. Maloclusiones en dentición mixta. Odont Moder [serie en intenet]. 2009. 6(62): 7 www.imbiomed.com.mx (consultada 12/10/2012)

35. Ortiz Godoy; Farías Mata, M. Perdida prematura de dientes temporales en pacientes de 5 a 8 años de edad asistidos en la clínica de odontopediatría Universidad Gran Mariscal de Ayacucho 2004-2005 www.ortodoncia.ws (consultada $12 / 10 / 2012)$

36. Gracia MF;Amayan B; Barrios Z. Perdida prematura de dientes primarios y su relación con edad y sexo en preescolares. Revista de Odontología de los Andes 2007;2 (2)

Recibido: 16-11-2013

Aceptado: 12-12-2013

Correspondencia: María Elena Guerra Coordinadora del Programa "El Binomio Madre e Hijo VIH/SIDA CAPEI/UCV" marielena05@gmail.com 58(212)6053800 